\title{
Quick but effective surgery for functional mitral regurgitation secondary to aortic valve disease
}

\author{
Masashi Komeda, MD, PhD, Osaka and Nagoya, Japan
} From the Department of Cardiovascular Surgery, Jinsenkai Hospital, Osaka; and Nagoya Heart Center, Nagoya,
Japan.
Read at The American Association for Thoracic Surgery Mitral Conclave, New York, New York, April 23-24,
2015.
Disclosures: Author has nothing to disclose with regard to commercial support.
Received for publication June 1, 2016; revisions received July 16, 2016; accepted for publication Aug 4, 2016;
available ahead of print Sept 17, 2016.
Address for reprints: Masashi Komeda, MD, PhD, Department of Cardiovascular Surgery, Jinsenkai Hospital,
8-2-22 Morofuku, Daito, Osaka, 574-0044 Japan (E-mail: zeek-m@bf7.so-net.ne.jp).
J Thorac Cardiovasc Surg 2017;153:275-7
0022-5223/\$36.00
Copyright @ 2016 by The American Association for Thoracic Surgery
http://dx.doi.org/10.1016/j.jtcvs.2016.08.015
Video clip is available online.

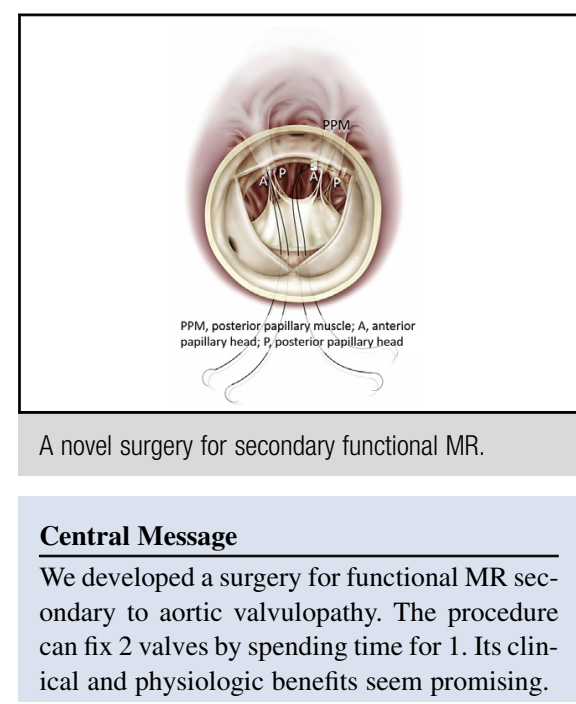

See Editorial Commentary page 278.

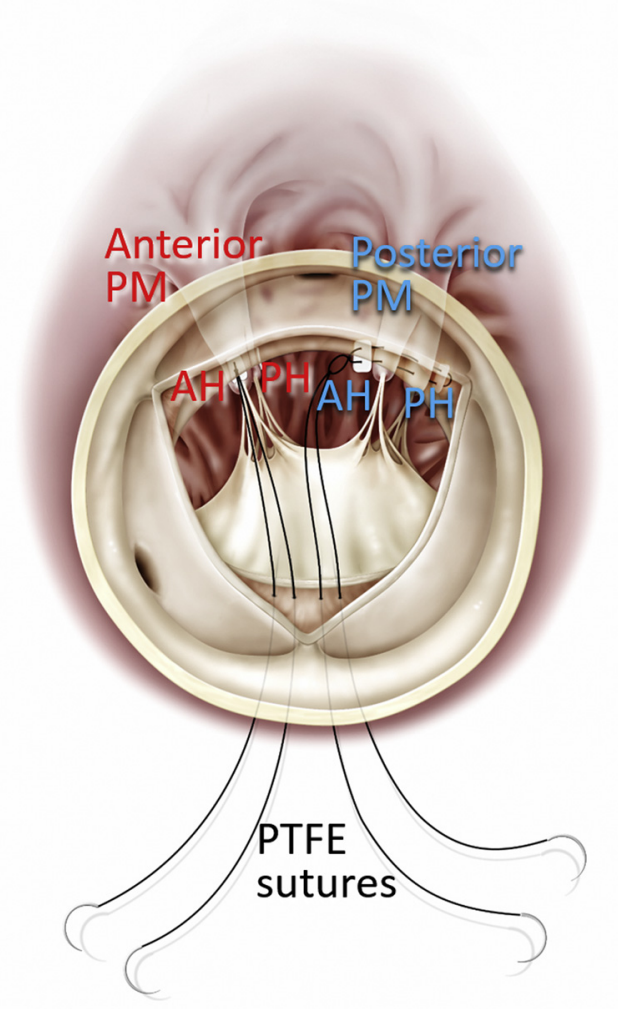

FIGURE 1. Modified relocation of PMs. Two papillary heads were connected by the PTFE suture in each PM, and the suture was externalized via subaortic curtain. The illustration of the posterior PM heads shows how to place a stitch to the 2 heads to connect them. $P M$, Papillary muscle; $A H$, anterior head; $P H$, posterior head; PTFE, polytetrafluoroethylene. 


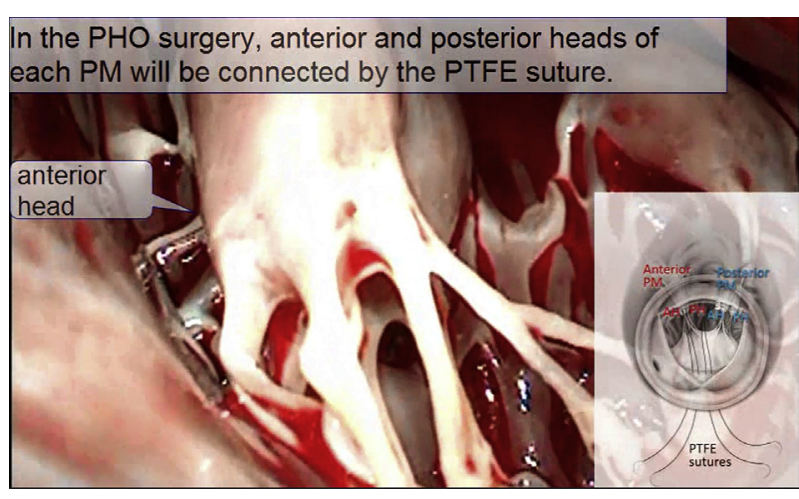

VIDEO 1. $A R$, Aortic regurgitation; $D d$, diastolic diameter; $D O E$, dyspnea on effort; $E F$, ejection fraction; $F M R$, functional mitral regurgitation; $L V A$, left ventricular aneurysm; $M A P$, mitral annuloplasty; $M R$, mitral regurgitation; $N C C$, noncoronary cusp; $N Y H A$, New York Heart Association; $P H O$, papillary heads optimization; $P M$, papillary muscle; $P T F E$, polytetrafluoroethylene; $R C C$, right coronary cusp; $S V R$, surgical ventricular restoration; $T R$, tricuspid regurgitation. Video available at: http://www.jtcvsonline.org/article/S00225223(16)31034-0/addons.

functional class was $3.5 \pm 0.7$. Echocardiography revealed an LV diastolic diameter of $60.2 \pm 9.8 \mathrm{~mm}, \mathrm{LV}$ ejection fraction of $31.0 \% \pm 14.3 \%$, MR degree of $3.5 \pm 0.7$, and estimated right ventricular pressure of $49.3 \pm 13.8 \mathrm{~mm} \mathrm{Hg}$. Preoperative tethering height of the mitral valve was $9.7 \pm 1.1 \mathrm{~mm}$. Paired $t$ test was used for statistical analysis.
During the operation, after an aortotomy, all cusps were excised, allowing exposure of both PMs and the AL by using a long-blade retractor. A 4-0 Teflon-pledgeted polytetrafluoroethylene (PTFE) suture was used to connect the posterior and anterior heads in each PM, because the posterior head supports the chordae for the posterior leaflet and anterior head for AL. The PTFE suture was then passed through the subaortic curtain toward the outside of the heart and left untied for a while (Figure 1 and Video 1). Then, the aortic valve procedure was completed. After terminating the cardiopulmonary bypass, the PTFE relocation sutures were pulled/relaxed and tied under transesophageal echocardiography guidance when the tethering and the MR was zero or minimal.

\section{RESULTS}

In the operation, all patients had aortic valve procedures; 10 bioprostheses, 2 valve repairs, 1 root reimplantation, and 1 Bentall procedure. Concomitant procedures were 3 tricuspid annuloplasties and 2 ascending/arch replacements. All patients had an uneventful recovery, except for 1 patient, an 86-year-old woman with mesenteric emboli due to shaggy aorta 2 weeks postoperatively.

Postoperative echocardiography revealed an LV diastolic diameter of $53.1 \pm 10.6 \mathrm{~mm}(P=.006$ vs preoperatively $)$, LV ejection fraction of $37.4 \% \pm 16.2 \%(P=$ not significant, .10), degree of MR of $0.8 \pm 0.6(P<.001)$, and estimated right ventricular pressure of $32.1 \pm 13.0 \mathrm{~mm}$ $\mathrm{Hg}(P=.017)$. Postoperative tethering height of the mitral valve was $4.6 \pm 1.1 \mathrm{~mm}(P<.001)$.
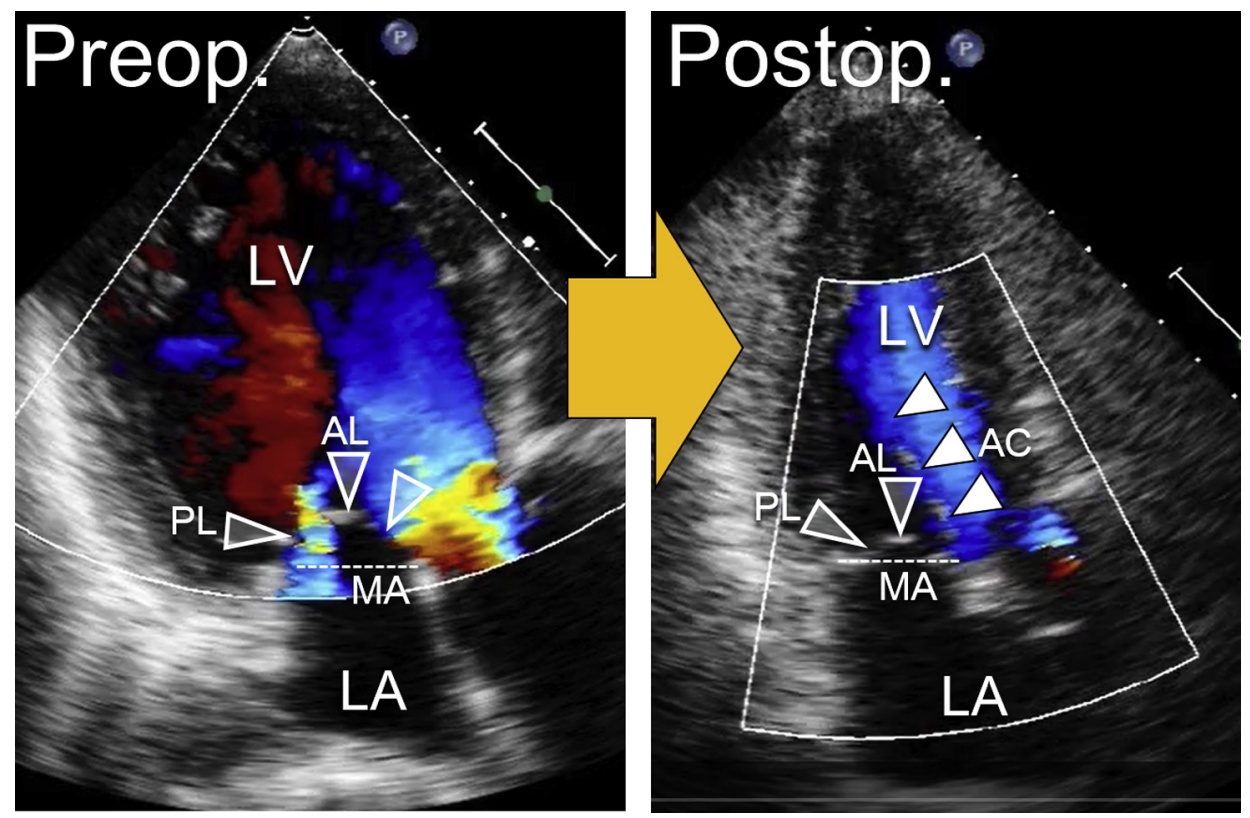

FIGURE 2. Echocardiography of a representative patient. A 64-year-old woman underwent the Bentall procedures and PHO relocation of the PMs via an aortic orifice. One year after the surgery, leaflets tethering, functional MR, and LV dilatation/sphericalization disappeared. Note that the patient did not receive mitral annuloplasty or left atriotomy. White triangular markers show artificial chordae for relocation. $L V$, Left ventricle; $A L$, anterior leaflet; $P L$, posterior leaflet; $M A$, mitral annulus; $L A$, left atrium; $A C$, artificial chordae. 
Among 8 patients with more than 12 months of followup, there was 1 late death; 1 patient, a 71-year-old man with chronic hemodialysis, died suddenly on day 60 . At $1010 \pm 577$ days after the surgery, LV diastolic diameter was $46.0 \pm 8.1 \mathrm{~mm}(P=.070)$, LV ejection fraction was $60.4 \% \pm 2.1 \%(P=.003)$, and MR degree was $1.5 \pm 0.6$ $(P<.035)$. Echocardiography of a representative patient is shown in Figure 2.

\section{DISCUSSION}

In case of severe aortic valve disease with dilated cardiomyopathy and moderate functional MR, the management of $\mathrm{MR}$ remains controversial. ${ }^{1-3} \mathrm{We}$ tried to perform effective double valve treatment by spending time for a single valve.

To do so, we applied the $\mathrm{PHO}^{5}$ method through an aortotomy to decrease the ischemic pump time; we saved approximately 40 minutes of ischemic time. We applied the method by attaching individual resuspension chorda to each PM because the patients had global LV dilatation/dysfunction and the anterior PM was dislocated.

So far, our procedure seems beneficial for those with functional MR and significant tethering secondary to aortic valvulopathy and those with a mitral annulus that is not overly dilated. Under this condition, we saved a significant amount of time. Moreover, it took less than 10 minutes to perform the PHO procedure via the aortic orifice. The procedure has another merit: accurate and effective tension control of the relocation sutures under the monitoring of transesophageal echocardiography with an off-pump beating condition.

\section{CONCLUSIONS}

The relocation method described may be one answer to the dilemma of treating functional MR secondary to aortic valvulopathy. It is in part ventricular treatment and may have a physiologic impact ${ }^{5}$ rather than valvular treatment, such as the M-clip. Midterm results are encouraging, and further investigation is warranted.

\section{References}

1. Schubert SA, Yarboro LT, Madala S, Ayunipudi K, Kron IL, Kern JA, et al. Natural history of coexistent mitral regurgitation after aortic valve replacement. J Thorac Cardiovasc Surg. 2016;151:1032-42.

2. Barreiro CJ, Patel ND, Fitton TP, Williams JA, Bonde PN, Chan V, et al. Aortic valve replacement and concomitant mitral valve regurgitation in the elderly Circulation. 2005;112:I-443-7.

3. Langer F, Rodriguez F, Ortiz S, Cheng A, Nguyen TC, Zasio MK, et al Subvalvular repair. Circulation. 2005;112:I-383-9.

4. Langer F, Schafers HJ. RING plus STRING: papillary muscle repositioning as an adjunctive repair technique for ischemic mitral regurgitation. J Thorac Cardiovasc Surg. 2007; 133:247-9.

5. Komeda M, Koyama Y, Fukaya S, Kitamura H. Papillary heads “optimization” in repairing functional mitral regurgitation. J Thorac Cardiovasc Surg. 2012;144: $1262-4$. 